2 Mantle flow geometry from ridge to trench beneath the Gorda-Juan de Fuca plate system

4

$5 \quad$ *Robert Martin-Short ${ }^{1}$, Richard M Allen ${ }^{1}$, Ian Bastow ${ }^{2}$, Eoghan Totten ${ }^{1,2}$, Mark Richards $^{1}$

14 [1] Department of Earth and Planetary Science, UC Berkeley

15 [2] Department of Earth Science and Engineering, Imperial College London

16 *Corresponding author email: rmartin-short@berkeley.edu

19 Resubmission of NGS-2015-04-00698A

20

21

22

23 
24 Tectonic plates are underlain by a low viscosity mantle layer, the asthenosphere.

25 Asthenospheric flow may be induced by the overriding plate or by deeper mantle

26 convection ${ }^{1}$. Shear strain due to this flow can be inferred using the directional

27 dependence of seismic wave speeds - seismic anisotropy. However, isolation of

28 asthenospheric signals is challenging; most seismometers are located on continents,

29 whose complex structure influences the seismic waves en-route to the surface. The

30 Cascadia Initiative, an offshore seismometer deployment in the US Pacific

31 Northwest, offers the opportunity to analyze seismic data recorded on simpler

32 oceanic lithosphere ${ }^{2}$. Here we use measurements of seismic anisotropy across the

33 Juan-de-Fuca and Gorda plates to reconstruct patterns of asthenospheric mantle

34 shear flow from the Juan-de-Fuca mid-ocean ridge to the Cascadia subduction zone

35 trench. We find that the direction of fastest seismic wave motion rotates with

36 increasing distance from the mid-ocean ridge to become aligned with the direction

37 of motion of the Juan-de-Fuca Plate, implying that this plate influences mantle flow.

38 In contrast, asthenospheric mantle flow beneath the Gorda Plate does not align with

39 Gorda Plate motion and instead aligns with the neighbouring Pacific Plate motion.

40 These results show that asthenospheric flow beneath the small, slow-moving Gorda

41 Plate is controlled largely by advection due to the much larger, faster-moving Pacific 42 Plate.

44 The Juan-de-Fuca plate system is the northernmost section of the Farallon slab, 45 which is approaching complete subduction beneath the North American continent ${ }^{3}$.

46 The system is subdivided into the Explorer, Juan-de-Fuca and Gorda segments, 
47 which subduct at $\sim 12 \mathrm{~mm} / \mathrm{yr}$ in a $\sim \mathrm{N} 60^{\circ} \mathrm{E}$ direction beneath the Cascadia $\operatorname{arc}{ }^{4,5}$. The

48 assemblage is undergoing rollback at $\sim 24 \mathrm{~mm} / \mathrm{yr}^{4}$ and rotating clockwise as the

49 Mendocino Triple Junction (MTJ) migrates northwards 4

50

51 Questions about the mantle flow geometry beneath Cascadia focus on interaction

52 between oceanic asthenosphere and the subducting slab ${ }^{6}$. Shear wave splitting, a

53 technique that quantifies the magnitude and direction of seismic anisotropy, can

54 address such questions ${ }^{6,7}$. Seismic anisotropy in the mantle develops due to the

55 lattice-preferred orientation (LPO) of various minerals ${ }^{8}$. Olivine, the main

56 component of the upper mantle, is highly anisotropic ${ }^{8,9}$. Simple shearing under

57 typical asthenosphere conditions yields olivine crystal alignment, with fast axes

58 corresponding to the shearing direction ${ }^{8}$. Shear waves traversing such a medium are

59 split into two orthogonal components, one of which is polarized in the fast direction.

60 A delay time $(\delta \mathrm{t})$ proportional to the strength and layer-thickness of the anisotropy

61 is acquired as the components transit the layer. The fast axis direction $(\phi)$ is used to

62 determine the shearing direction and by inference the mantle flow geometry?

63

64 Onshore studies in Cascadia reveal uniformly trench perpendicular anisotropy,

65 indicative of sub-slab mantle flow ${ }^{4,5}$. Cascadia is unusual; most subduction zones

66 demonstrate trench-parallel splitting6. This has been variously interpreted as

67 rollback-induced flow ${ }^{6}$, the influence of B-type olivine LPO in the mantle wedge ${ }^{9}$, or

68 the consequence of strong radial anisotropy in steeply dipping, entrained flow ${ }^{10}$. 
70 We analyze data from Cascadia Initiative seismometer deployments ${ }^{2}$, including 27

71 onshore Transportable Array (TA) sites and 70 ocean bottom seismometers (OBS),

72 deployed in ten-month phases at 160 sites $^{2}$. We analyze OBS data from years 1-3 of

73 the Cascadia Initiative and 4 years of records from the NEPTUNE cabled seafloor

74 observatory ${ }^{11}$. Public data from the X9 OBS array, deployed along the Blanco

75 Fracture Zone in $2012-2013^{2}$ are also utilized (supplementary information, S2).

77 Splitting parameters $\phi$ and $\delta$ t are determined for each station-event pair using two

78 open-source software packages, before results are stacked to produce a single

79 measurement at each site (see methods). Shear wave splitting with OBS data is

80 challenging due to high noise levels within the $S$ frequency band ${ }^{12,13}$ and uncertainty

81 in instrument orientation ${ }^{14}$. We generally obtain 1-4 good quality measurements

82 per offshore station, compared to 8-15 results for the onshore sites (supplementary

83 information, S3-S6).

85 The TA stations produce a uniform splitting pattern along the length of the

86 subduction zone (figure 1). The mean fast direction and delay times are $N 72^{\circ} \mathrm{E}$ and

$871.34 \mathrm{~s}$ respectively, in agreement with previous studies and sub-parallel to the

88 subduction direction of $\mathrm{N} 60^{\circ} \mathrm{E}^{4,5}$. Offshore stations on the Juan-de-Fuca plate

89 display a more complicated pattern: except for a single, ridge-parallel result near

90 Cobb Hotspot, fast splitting directions (FSD) vary between the trench perpendicular

91 and absolute plate motion (APM) direction. Alignment with the Juan-de-Fuca APM 
92 direction increases towards the trench (figure 2). The FSD then rotate into the

93 subduction direction as one moves onshore.

94

95 Sites on the Gorda plate produce a highly uniform pattern, but are neither aligned

96 with Gorda APM nor the subduction direction. Their mean FSD of N66 ${ }^{\circ} \mathrm{W}$ aligns with

97 the motion of Pacific plate $\left(\sim \mathrm{N}^{\circ} 7^{\circ} \mathrm{W}^{4}\right)$ and with the ridge-perpendicular orientation

$98\left(\sim \mathrm{N} 67^{\circ} \mathrm{W}\right)$. A marked change in FSD is observed just east of the trench in this region,

99 where the fast directions rotate approximately $70^{\circ}$ into a trench-perpendicular

100 orientation (Figure 2a). Results from stations situated on the Pacific plate align well

101 with APM, featuring a mean direction of $\mathrm{N} 60^{\circ} \mathrm{W}$.

102

103 This study compliments previous shear wave splitting results from ocean basins ${ }^{15,16}$

104 and enhances coverage of the region. A notable feature of the existing onshore

105 pattern is the arcuate splitting geometry observed south of the MTJ in northern

106 California, which follows the southern edge of the down-going Gorda slab ${ }^{4,17}$ (Figure

107 1). The subducting slab is imaged by body wave tomography as a segmented, high

108 velocity anomaly with a 'gap' beneath northern Oregon ${ }^{18}$. This 'gap' does not appear

109 to influence the splitting pattern, however.

110

111 Limited back-azimuthal coverage makes it difficult to model dipping or multi-layer

112 regional anisotropy in our study. We follow previous teleseismic splitting studies ${ }^{4,5}$

113 of this area in interpreting a single anisotropic layer. 
115 On oceanic plates, the dominant splitting signal likely arises from a combination of

116 fossil anisotropy in the lithosphere and viscous shearing of the asthenosphere by

117 plate motion ${ }^{7}$. According to the model of Nishimura and Forsyth ${ }^{19}$, the lithospheric

118 component should lie in the fossil spreading direction, while the asthenospheric

119 component should align with the direction of present day mantle flow. Both are

120 parallel to the spreading direction close to mid-ocean ridges, but diverge beneath

121 older lithosphere as the asthenosphere is dragged in to the APM direction ${ }^{19}$. Shear

122 wave splitting studies of the East Pacific Rise ${ }^{15}$ and in French Polynesia ${ }^{16}$ generally

123 support this idea.

124

125 Given realistic estimates of $50 \mathrm{~km}, 4 \%$ and $4.6 \mathrm{~km} / \mathrm{s}$ for the thickness, percentage

126 anisotropy, and shear wave velocity for the Juan-de-Fuca plate, respectively, a

127 lithospheric splitting time contribution of $0.43 \mathrm{~s}$ is predicted ${ }^{4,7}$. This is significantly

128 smaller than the OBS splitting times, implying that the asthenosphere is an

129 important source of anisotropy.

130

131 The rotation of FSDs into the APM orientation east of the Juan-de-Fuca ridge implies

132 the influence of competing flow components. A variety of anisotropic fabrics might

133 be expected in the vicinity of a mid-ocean ridge: upwelling asthenosphere in

134 response to passive spreading, oriented melt pocket anisotropy along the ridge itself

135 due to dyke intrusion ${ }^{20}$, lateral flow away from the ridge ${ }^{21}$ and basal drag fabrics as

136 the plate moves away from the ridge ${ }^{19}$.

137 
138 Splitting directions close to the Juan-de-Fuca ridge generally lie between APM and

139 ridge-perpendicular direction, suggesting that lateral flow and basal drag are the

140 strongest influences. We do not see a concentration of null results at stations located

141 close to the ridge (see methods), suggesting that the influence of vertically oriented

142 LPO due to upwelling is minimal or confined to a narrow region.

143

144 One exception to the pattern occurs at site J39, just east of Axial Seamount. The

145 splitting parameters here are well constrained and suggest strong ridge-parallel

146 anisotropy (supplementary information, S7). This may be the result of aligned

147 pockets of melt present near the ridge axis as observed on land in Ethiopia, a

148 subaerial region of incipient oceanic spreading 20.

150 On the Gorda section of the plate system there is no significant variation in FSD with

151 distance from the ridge. The FSD are instead well aligned with the direction of

152 Pacific plate motion and with results from the Pacific plate west of the Gorda ridge

153 and south of the Mendocino Fracture Zone. This implies that asthenospheric flow

154 beneath the Gorda plate, west of the trench, is determined by the regional pattern of

155 shearing induced by the north-westward motion of the Pacific plate, which moves at

$156 \sim 60 \mathrm{~mm} / \mathrm{yr}^{22}$. An alternative suggestion posits that because flow in this region is

157 ridge perpendicular, it is driven primarily by spreading of the Gorda ridge. This is

158 less likely given the apparent limited influence of the faster-spreading Juan-de-Fuca

159 plate on the splitting pattern to the north. The splitting geometry on Gorda does not 
160 suggest major contributions from motion of the plate itself or rollback of the trench,

161 which operates at less than half the speed of the Pacific plate.

163 The uniform, subduction-parallel splitting pattern seen on the North American plate

164 east of the trench is interpreted as a consequence of entrained mantle material

165 beneath the down-going slab. Fossil anisotropy in the continental lithosphere and

166 subducted slab has been shown to be insufficient to explain the observed high delay

167 times ${ }^{4}$, thus implying an asthenospheric source 4 . Furthermore, the mantle wedge is

168 thin or non-existent within most of study area, so the only region thick enough to

169 produce delay times commensurate to those observed is the sub-slab mantle ${ }^{3,4}$.

170 Nevertheless, onshore FSD tend towards North American APM at great distances

171 from the trench (figure 2b), suggesting some influence from plate-motion induced

172 flow in the mantle wedge, or from lithospheric anisotropy. There is no significant

173 change in delay times, however (supplementary information, S8).

174

175 Immediately east of the trench of the Juan-de-Fuca plate, splitting geometry rotates

176 smoothly from an APM-parallel direction into a trench-perpendicular direction. This

177 is indicative of entrained easterly flow beneath the slab. In contrast, across the

178 Gorda-North America plate boundary there is a sharp change in FSD (figure 2a).

179 This is difficult to justify with a single layer interpretation because it would imply

180 dramatic changes in flow direction. Instead, this region could host two layers of

181 mantle flow: A shallow layer induced by motion of the Pacific plate and a deeper

182 layer related to entrainment by the subducting slab. 
184 Our observation provides a test for the models of Conrad et al. ${ }^{1}$ and Debayle \&

185 Ricard ${ }^{23}$, which suggest that plates moving slower than $40 \mathrm{~mm} / \mathrm{yr}^{23}$ and within

$186500 \mathrm{~km}$ of a constructive plate margin ${ }^{1}$ are less able to influence asthenospheric

187 flow. Both Gorda and Juan-de-Fuca meet these criteria, so the observation that Juan-

188 de-Fuca does affect the asthenosphere perhaps sets lower bounds on the age and

189 speed of a tectonic plate that can induce asthenospheric flow.

190

191 The Gorda plate is young $\left(<10 \mathrm{My}^{24}\right)$, has a low absolute velocity ${ }^{22}$, is undergoing

192 internal deformation ${ }^{24}$ and may have had its current APM for less than $2 \mathrm{Ma}^{24}$. In

193 contrast, the neighboring Pacific plate is large, intact and fast moving. We have

194 constructed a 2D model of this situation using the method of Hager \& O'Connell ${ }^{25}$ to

195 show that Pacific plate motion is capable of generating westward flow beneath the

196 width of the Gorda plate, assuming that flow is largely confined to the uppermost

197 mantle within a thin, low viscosity asthenosphere (viscosity contrast 100, channel

198 thickness $100 \mathrm{~km}^{26}$ - see methods) beneath Gorda. This simple model demonstrates

199 the plausibility of our interpretation of the splitting pattern (figure 3).

200

201 This leads to discussion of the arcuate spitting geometry observed south of the MTJ

202 and interpreted as flow forced eastwards around the slab edge by rollback ${ }^{4}$. This

203 pattern, however, could be asthenospheric flow induced by drag from the $\mathrm{N} 60^{\circ} \mathrm{W}$

204 drifting Pacific plate. A larger scale arcuate splitting pattern, situated much further 
205 east, may instead be the result of deep toroidal flow around the slab edge, which

206 extends below 400km in this region ${ }^{17}$ (supplementary information, S9)

207

208 In summary, we propose that the splitting observed on the Juan-de-Fuca plate

209 system is mainly the result of APM-driven asthenosphere flow. At depth, below the

210 Cascada fore-arc, the downgoing slab entrains underlying mantle material. West of

211 the subduction zone, the Juan-de-Fuca plate is sufficiently large and fast moving to

212 influence mantle flow geometry while the Gorda plate is not. Flow directly beneath

213 Gorda is instead induced by Pacific plate motion. This places bounds on the size of

214 plate capable of inducing asthenospheric flow.

215

\section{References in main text}

217

218

219 [1] Conrad, C. Behn, M. \& Silver, P. Global mantle flow and the development of seismic

220 anisotropy: differences between the oceanic and continental upper mantle. J. Geophys.

221 Res., 112(B7) (2007).

222

223 [2] Toomey, D., et al. The Cascadia initiative: A sea change in seismological studies of

224 subduction zones. Oceanography. 27(2), 138-150 (2014).

225 [3] Riddihough, R. Recent movements of the Juan de Fuca plate system. J. Geophys. Res. 89, 226 6980-6994 (1984). 
227 [4] Eakin, C., et al. Seismic anisotropy beneath Cascadia and the Mendocino triple junction:

228 Interaction of the subducting slab with mantle flow. Earth Planet Sci. Lett.. 297, 627-632

229 (2010).

230 [5] Currie, C., et al. Shear wave anisotropy beneath the Cascadia subduction zone and 231 western North American craton. Geophys. J. Int. 157, 341-353 (2004).

232 [6] Long, M. \& Silver, P. The subduction zone flow field from seismic anisotropy: a global 233 view. Science 319, 315-318 (2008).

234 [7] Silver, G. \& Chan, W. Shear wave splitting and subcontinental mantle deformation. J. 235 Geophys. Res. 96, 16429-16454 (1991).

236 [8] Nicolas, A. \& Christensen, N. Formation of Anisotropy in Upper Mantle Peridotites-A 237 Review. Composition, structure and dynamics of the lithosphere-asthenosphere system, 111238123 (1987).

239

240 [9] Karato, S., Katayama, I. \& Skemer, P. Geodynamic significance of seismic anisotropy of 241 the upper mantle: new insights from laboratory studies. Ann. Rev. Earth Planet. Sci. 36, 5924295 (2008).

243 [10] Song, T. \& Kawakatsu, H. Subduction of oceanic asthenosphere: Evidence from sub-slab 244 seismic anisotropy. Geophys. Res. Lett. 39, L17301 (2012).

245 [11] Heesemann, M., et al. Ocean Networks Canada: From geohazards research laboratories 246 to Smart Ocean Systems. Oceanography 27, 151-153 (2014). 
247 [12] Bell, S., Forsyth, D. \& Ruan, Y. Removing Noise from the Vertical Component Records of 248 Ocean-Bottom Seismometers: Results from Year One of the Cascadia Initiative. Bull. Seis. Soc. 249 Am. 105, 300-313, (2014).

250 [13] Webb, S. Broadband seismology and noise under the ocean. Rev. Geophys., 36(1), 105251142 (1998).

252 [14] Lodewyk, J. \& Sumy, D. Cascadia Amphibious Array Ocean Bottom Seismograph 253 Horizontal Component Orientations. OBSIP Management Office (2014). At

254 http://www.obsip.org/experiments/experiment-list/2011/cascadia

255 [15] Wolfe, C., and Solomon, S. Shear-wave splitting and implications for mantle flow 256 beneath the MELT region of the East Pacific Rise. Science 280.5367, 1230-1232 (1998) 257

258 [16] Fontaine, F., et al. Upper-mantle flow beneath French Polynesia from shear wave 259 splitting. Geophys. J. Int. 170(3), 1262-1288 (2007).

260

261 [17] Zandt, G., \& Humphreys, E. Toroidal mantle flow through the western US slab 262 window. Geology 36(4), 295-298 (2008).

263 [18] Obrebski, M., et al. Slab-plume interaction beneath the Pacific Northwest. Geophys. Res. 264 Lett. 37(14), L14305 (2010).

265 [19] Polet, J., and Kanamori, H. Upper-mantle shear velocities beneath southern California 266 determined from long-period surface waves. Bull. Seis. Soc. Am. 87(1), 200-209 (1997).T0

267 [19] Nishimura, C. \& Forsyth, D. The anisotropic structure of the upper mantle in the Pacific. 268 Geophys. J. Int. 96, 203-229 (1989). 
269 [20] Kendall, J., et al. Magma-assisted rifting in Ethiopia. Nature 433, 146-148 (2005).

270 [21] Blackman, D. \& Kendall, J. Sensitivity of teleseismic body waves to mineral texture and 271 melt in the mantle beneath a mid-ocean ridge. Phil. Trans. R. Soc. Lond. A. 355, 217-231 272 (1997).

273 [22] Gripp, A. \& Gordon, R. Young tracks of hotspots and current plate velocities. Geophys. J. 274 Int. 150, 321-361 (2002).

275 [23] Debayle, E. \& Ricard, Y. Seismic observations of large-scale deformation at the bottom 276 of fast-moving plates. Earth Planet. Sci. Lett. 376, 165-177 (2013).

277

278 [24] Chaytor, J., et al. Active deformation of the Gorda plate: Constraining deformation 279 models with new geophysical data. Geology 32(4), 353-356 (2004)

280

281 [25] Hager, B. H. \& O'Connell, R. J. A simple global model of plate dynamics and mantle 282 convection. J. Geophys. Res. 86, 4843-4867 (1981).

283

284 [26] Fjeldskaar, W. Viscosity and thickness of the asthenosphere detected from the 285 Fennoscandian uplift. Earth Planet. Sci. Lett. 126(4), 399-410 (1994).

286 [27] Wessel, P. \& Smith, W. New, improved version of Generic Mapping Tools released. Eos, 287 Trans. Am. Geophys. U. 79, 579-579 (1998).

288 [28] Wüstefeld, A., et al. Identifying global seismic anisotropy patterns by correlating shear289 wave splitting and surface-wave data. Phys. Earth Planet. Int. 176, 198-212 (2009). 
290 [29] Porritt, R., Allen, R. \& Pollitz, F. Seismic imaging east of the Rocky Mountains with

291 USArray Earth Planet. Sci. Lett. 402, 16-25 (2014).

292 [30] Hayes, G., Wald, D. \& Johnson, R. Slab1.0: A three-dimensional model of global

293 subduction zone geometries. J. Geophys. Res. 117, B01302 (2012).

\section{Corresponding Author}

295 Robert Martin-Short

296 Email: rmartin-short@berkeley.edu

297

\section{Acknowledgements}

299 The data used in this research was provided by instruments from the Ocean Bottom

300 Seismograph Instrument Pool (http://www.obsip.org), which is funded by the

301 National Science Foundation under cooperative agreement OCE-1112722. The

302 work benefitted from discussions with J. Lodewyk, A. Frassetto and C. Eakin. We also

303 thank the editor and three anonymous reviewers for their helpful comments. GMT

304 (Wessel \& Smith ${ }^{27}$ ) and MATLAB where used to create the figures.

305

306 Author contributions

307 This study was carried out and written up by Robert Martin-Short, under

308 supervision of Richard Allen. Ian Bastow assisted with data analysis and helped

309 write the paper. Eoghan Totten and Mark Richards provided advice and minor

310 modifications to the text.

\section{Competing financial interests statement}


313 I declare that the authors have no competing interests as defined by Nature

314 Publishing Group, or other interests that might be perceived to influence the results

315 and/or discussion reported in this article.

\section{$316 \quad$ Figure captions}

\section{$317 \quad$ Figure 1}

\section{Stacked splitting results determined by this study (red bars) and previous} work (back bars; from Eakin et al. $^{4}$ and Wustefeld et al. ${ }^{28}$ ).

321 The displayed tomography is a $100-400 \mathrm{~km}$ vertical average through the DNA13 P-

322 wave velocity model of Porritt ${ }^{29}$. This depth range corresponds to that part of the

323 asthenosphere considered most likely to be the source of the observed anisotropy ${ }^{9}$.

324 All splits are plotted at seismography station/OBS locations. Black lines indicate

325 plate boundaries, while the red lines are slab depth contours spaced at $10 \mathrm{~km}$

326 intervals ${ }^{30}$. Black arrows show the direction and magnitude of absolute plate motion

327 in a hotspot reference frame ${ }^{23}$, while purple arrows show the subduction direction ${ }^{4}$

328 Insert maps show regions featuring a high concentration of splitting results.

329

330

331

332

333

334 from the trench.

335 2A displays results with latitudes between the Mendocino Triple Junction (MTJ) and

336 the southern tip of the Blanco Fracture Zone. 2B shows sites between latitudes of 337 the southern and northern tips of the Juan-de-Fuca ridge. In 2A, one population of 
338 splits lies west of the trench and is aligned with Pacific plate motion, while another

339 aligns with the subduction direction. 2B shows continuous variation in splitting

340 direction with trench distance. Blue and red markers indicate offshore and onshore

341 results respectively. Error bars indicate the 95\% confidence interval.

\section{$342 \quad$ Figure 3}

344 Two-dimensional modeling to simulate mantle flow below the Gorda plate as

345 induced by motion of the Pacific plate.

346 The green plate is stationary while the red plate moves to the left at $60 \mathrm{~mm} / \mathrm{yr}$. This

347 approximates the situation in profile perpendicular to the Gorda ridge (see methods

348 for more detail). The setup consists of an 'asthenosphere' from $50-150 \mathrm{~km}$ and an

349 'mesosphere' below. In our preferred model (3A), the viscosity of the mesosphere is

350100 times that of the asthenosphere.

351 3B shows details of the model set-up, including the imposed periodic surface

352 velocity field, region of interest and large scale induced flow structure. The motion

353 of the red plate is seen to generate flow beneath the adjacent stationary plate.

$355 \quad$ Methods

357 Shear wave splitting

358 We determine the splitting parameters $\phi$ and $\delta \mathrm{t}$ for each station-event pair using

359 Splitlab ${ }^{31}$ and SHEBA ${ }^{32}$. Splitlab uses three standard techniques: the rotation-

360 correlation method (RC; Bowman and $\mathrm{Ando}^{33}$ ), the minimum energy method (SC; 
361 Silver and $\mathrm{Chan}^{8}$ ) and the eigenvalue method (EV; Silver and $\mathrm{Chan}^{8}$ ). This allows

362 measurement classification as 'good', 'fair' or 'poor' according to the criteria of

363 Wustefeld \& Bokelmann ${ }^{34}$. SHEBA uses the eigenvalue method alone and

364 incorporates a cluster analysis algorithm, thus decreasing subjectivity in phase

365 arrival picking 32 . A total of 631 'fair' or 'good' measurements were made and

366 subsequently stacked using the method of Wolfe and Silver ${ }^{35}$. This number includes

367 high quality null results, which occur where the anisotropy is very weak, or aligned

368 parallel or perpendicular to the initial polarization of the seismic wave ${ }^{34}$ (see

369 supplementary information S3 and S5 for more information). We used events with

370 moment magnitudes greater than 6.0 and with epicentral distances of between 85

371 and 130 degrees. Teleseismic SKS and SKKS phases where utilized because their

372 passage through the core as P-waves removes source-side anisotropic effects7

373 Given that the lower mantle is approximately isotropic, the main splitting signal

374 source observed in teleseismic studies is likely within the upper $400 \mathrm{~km}$ of earth

375 structure, directly beneath the seismometers ${ }^{7}$.

376

377 The short deployment time of the OBS stations and small number of high quality

378 splitting results obtained limits backazimuthal converge and makes difficult to

379 model this dataset with more than a single layer of anisotropy. Given this constraint,

380 we chose not to include information about backazimuth in the stacking process.

382 Shear wave splitting of OBS data is complicated by the potential for component

383 misorientation (e.g. Lodewyk ${ }^{14}$ ). This arises because OBS instruments settle on the 
384 seabed in unknown orientations that must be determined after recovery in order to

385 rotate the horizontal components into the true 'East' and 'North' directions. The

386 horizontal orientations of the Cascadia Initiative and X9 stations were determined

387 using the surface wave polarization method of Stachnik ${ }^{36}$. The accuracy of the

388 results was then checked during the splitting process by comparing initial

389 polarization estimates to backazimuth directions and ensuring separation of

390 approximately 0 or 180 degrees.

391

392 A further check on the orientations can be carried out by virtue of how the three

393 methods respond to misaligned components ${ }^{37}$. It has been shown that $\mathrm{EV}$ and RC

394 splitting time estimates are unaffected by component misorientation, whereas small

395 inaccuracies in orientation introduce large errors for the SC method ${ }^{37}$. Our

396 measurements were only characterized as 'good' or 'fair' when there was

397 satisfactory agreement between the delay time predictions of the three methods. SC

398 method results are reported singularly in this paper because this technique has

399 been determined to be least sensitive to noise and exhibits the highest accuracy

400 proximal to null measurements ${ }^{34}$.

401

402 High levels of long period noise are present in the OBS data ${ }^{12,13}$. Filtering was used

403 to optimize noise reduction without unduly compromising the splitting

404 measurements. The characteristic frequency of teleseismic SKS waves ranges

405 between $0.08-0.13 \mathrm{~Hz}$ but most onshore studies utilize bandpass filters such as 0.02 -

$4060.20 \mathrm{~Hz}$, which capture the full range of SKS energy ${ }^{3,7}$. The presence of strong $0.16-$ 
$407 \quad 0.2 \mathrm{~Hz}$ secondary microseismic noise peaks in the OBS data ${ }^{12}$, however, means that

408 such filter bands are not typically useful in this case. OBS data is further affected by

409 strong compliance noise ranging from $0.01-0.04 \mathrm{~Hz}$, attributed to infragravity

410 waves ${ }^{11}$. This suggests an optimal filter band close to the 'noise notch' of $0.03-0.1 \mathrm{~Hz}$,

411 as identified by Webb ${ }^{13}$. Typically we choose a region of $0.05-0.15 \mathrm{~Hz}$, but employ

412 frequencies between 0.03 and $0.18 \mathrm{~Hz}$ on an event-by-event basis to optimize the

413 signal-to-noise ratio (SNR). In order to limit subjectivity many events had their

414 splitting parameters determined in multiple frequency bands and multiple time

415 windows. Only events with SNR greater than 4.0 were used in the stack. Upper filter

416 corner frequencies below $0.14 \mathrm{~Hz}$ were omitted to avoid signal energy reduction,

417 which makes measurements appear increasingly null. For further details, see S2-S5

418 of the supplementary information.

419

420 Geodynamic modeling

421

422 Our simple two-dimensional (2D) model of the mantle flow field beneath diverging

423 plates was constructed as a test of our interpretation of the splitting geometry

424 observed beneath the Gorda plate. The propagator matrix method for 2D periodic

425 flow given in the appendix of Hager and O'Connell 25 was used to solve for

426 instantaneous, incompressible, Newtonian viscous (Stokes) flow with piecewise-

427 constant horizontal (plate) motions imposed at the top of the mantle. Solutions are

428 obtained in Fourier series form with periodic boundary conditions horizontally. To

429 approximate the situation along a profile perpendicular to the Gorda ridge, we 
430 model one plate as stationary while the other diverges at a constant speed

$431(60 \mathrm{~mm} / \mathrm{yr})$. We focus on flow within a $400 \mathrm{~km}$ horizontal window centered at the

432 velocity jump, and choose a horizontal periodic boundary condition whose

433 fundamental length scale is much larger than this window length (Figure 3, bottom

434 panel). We follow Richards et al. ${ }^{38}$ by assuming a two-layer structure featuring a

435 thin, low viscosity and thick, underlying mantle layer. We base our viscosity contrast

436 and layer thickness estimates $(100 \mathrm{~km}$ and a viscosity contrast of 100$)$ on the work

437 of Fjeldskaar ${ }^{26}$, although we acknowledge that the width and viscosity of the

438 asthenosphere is poorly constrained (supplementary information, S10). Recent

439 seismic constraints, especially seismic anisotropy studies beneath the Pacific Plate ${ }^{39}$

440 , suggest strongly that the base of the highly anisotropic asthenosphere is at

441 approximately $200 \mathrm{~km}$ depth, which is consistent with geodynamic constraints as

442 long as the viscosity contrast is at least 2-3 orders of magnitude ${ }^{40}$. Thus, our choice

443 remains somewhat arbitrary, although the thickness and viscosity parameters we

444 employ reflect the findings of recent studies. Our model extends to $660 \mathrm{~km}$ in depth,

445 where the vertical flow field is set to zero at the bottom of the layer. Figure $3 \mathrm{~A}$

446 shows our preferred model, where the asthenosphere viscosity is reduced by a

447 factor of 100 . The model does not account for complicated features such as the 3D

448 plate geometry or the subduction zone, but clearly the weak asthenosphere causes

449 flow to be induced immediately beneath the stationary plate that is strongly aligned

450 with motion of the moving plate. We therefore propose that the large, fast-moving

451 Pacific plate induces asthenospheric flow beneath the small, fragmented, slow-

452 moving Gorda plate that is strongly aligned with Pacific plate motion, as observed. 
454 Data availability

455

456 The facilities of IRIS Data Services, and specifically the IRIS Data Management

457 Center, were used for access to waveforms, related metadata, and/or derived

458 products used in this study. IRIS Data Services are funded through the Seismological

459 Facilities for the Advancement of Geoscience and EarthScope (SAGE) Proposal of the

460 National Science Foundation under Cooperative Agreement EAR-1261681

461

462 The DNA13 North American tomography model, which was used in the creation of

463 figure 1, can be downloaded from

464 http://seismo.berkeley.edu/ rallen/pub/2014porritt/data.php

465

466 The high-resolution bathymetry/topography dataset used in the creation of

467 supplementary information S2A was obtained from

468 http://www.gebco.net/data_and_products/gridded_bathymetry_data/gebco_30_sec

469 ond grid/

470

471 Shear wave splitting measurements from previous studies where obtained from

472 http://splitting.gm.univ-montp2.fr/DB/

473 We plan to add our new results to this database.

474

475 Code availability 
476 The shear wave splitting software packages Splitlab and Sheba are publically

477 available:

478 The version of Splitlab used in this project can be downloaded from

479 https://robporritt.wordpress.com/software/

480

481 Sheba can be downloaded from https://github.com/jwookey/sheba

482

483 The code used to orient the OBS instruments can be obtained from

484 http://www.obsip.org/data/obs-horizontal-orientation

485

486 We have opted not to make the code associated with our geodynamic modeling

487 study available because it is tailored to a very specific situation and more generic

488 software based on the method of Hager \& O'Connell25 is already widely available.

489 However, we would be happy to provide our code if requested by email.

490

491 References only in methods

492 [31] Wüstefeld, A., et al. SplitLab: A shear-wave splitting environment in Matlab. Comp.

493 Geosci. 34, 515-528 (2008).

494 [32] Wüstefeld, A., et al. A strategy for automated analysis of passive microseismic data to 495 image seismic anisotropy and fracture characteristics. Geophysical Prospecting 58.5, 755-

$496773(2010)$ 
497 [33] Bowman, J. \& Ando, M. Shear-wave splitting in the upper-mantle wedge above the

498 Tonga subduction zone. Geophys. J. Int. 88, 25-41 (1987).

499 [34] Wüstefeld, A. \& Bokelmann, G. Null detection in shear-wave splitting measurements.

500 Bull. Seis. Soc. Am. 97, 1204-1211 (2007).

501 [35] Wolfe, C. \& Silver, P. Seismic anisotropy of oceanic upper mantle: Shear wave splitting 502 methodologies and observations. J. Geophys. Res. 103, 749-771 (1998).

503 [36] Stachnik, J. et al. Determination of New Zealand ocean bottom seismometer orientation 504 via Rayleigh-wave polarization. Seis. Res. Lett. 83, 704-713 (2012).

505 [37] Tian, X. et al. SKS splitting measurements with horizontal component misalignment.

506 Geophys. J. Int. 185, 329-340 (2011).

507 [38] Richards, M., et al. Role of a low-viscosity zone in stabilizing plate tectonics:

508 Implications for comparative terrestrial planetology. Geochem., Geophys., Geosyst. 2(8), 1026

509 (2001).

510

511 [39] Nettles, M., \& Dziewoński, A. Radially anisotropic shear velocity structure of the upper

512 mantle globally and beneath North America. Geophys. J. Int. 113.B2 (2008)

513

514 [40] Paulson, A., \& Richards, M. On the resolution of radial viscosity structure in modeling

515 long-wavelength postglacial rebound data. Geophys. J. Int. 179.3, 1516-1526 (2009) 


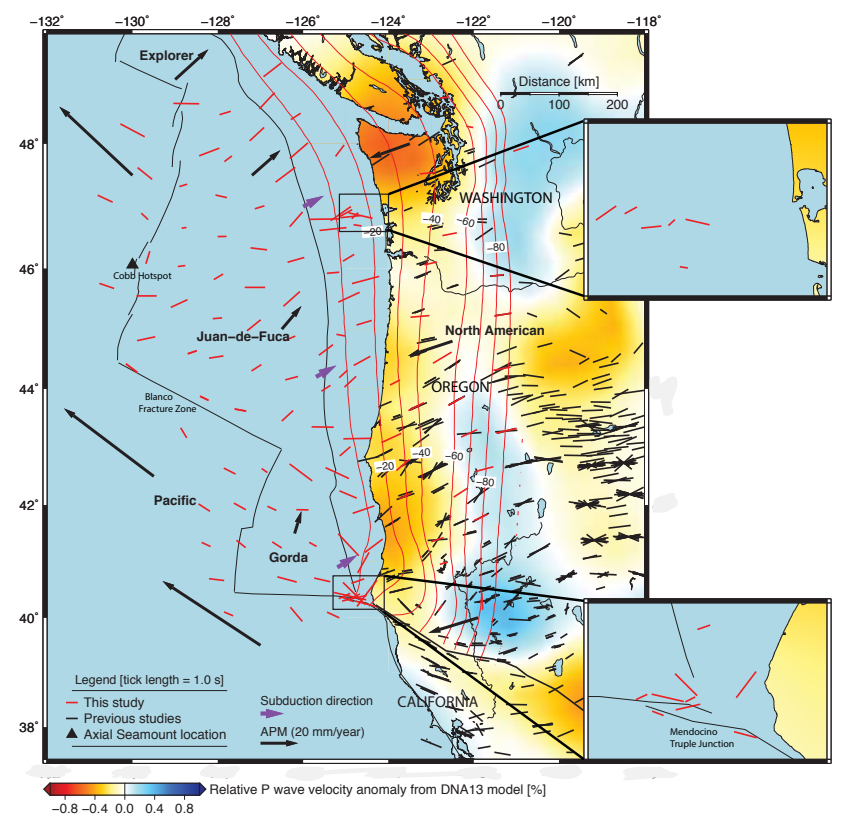




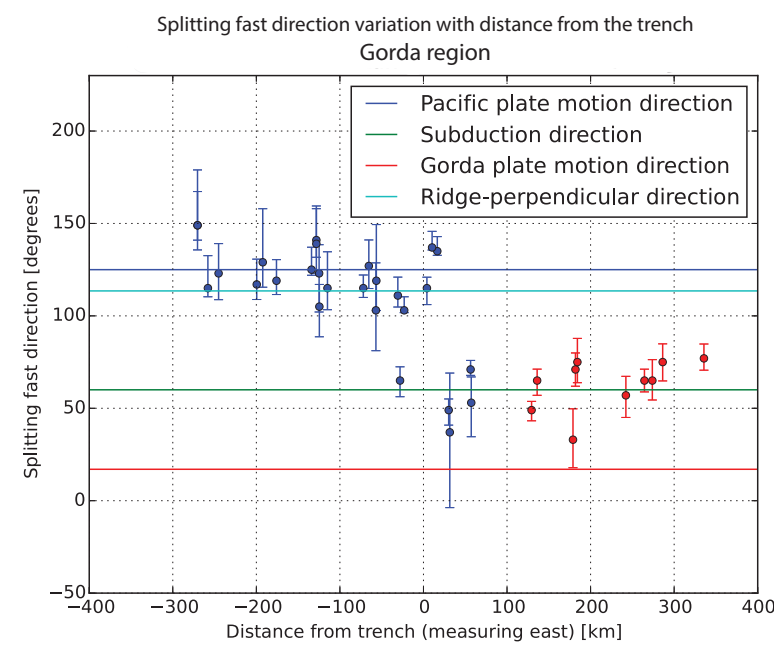

$2 \mathrm{~A}$

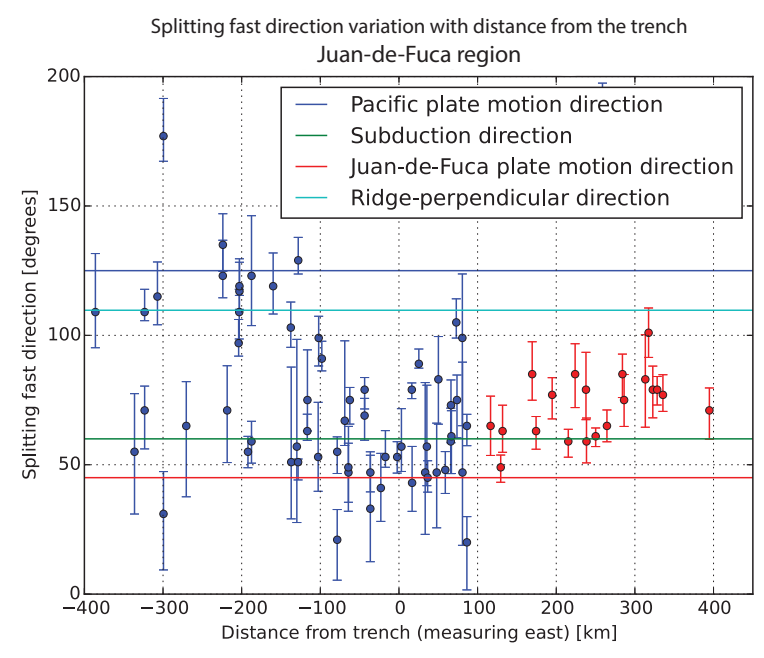

2B 

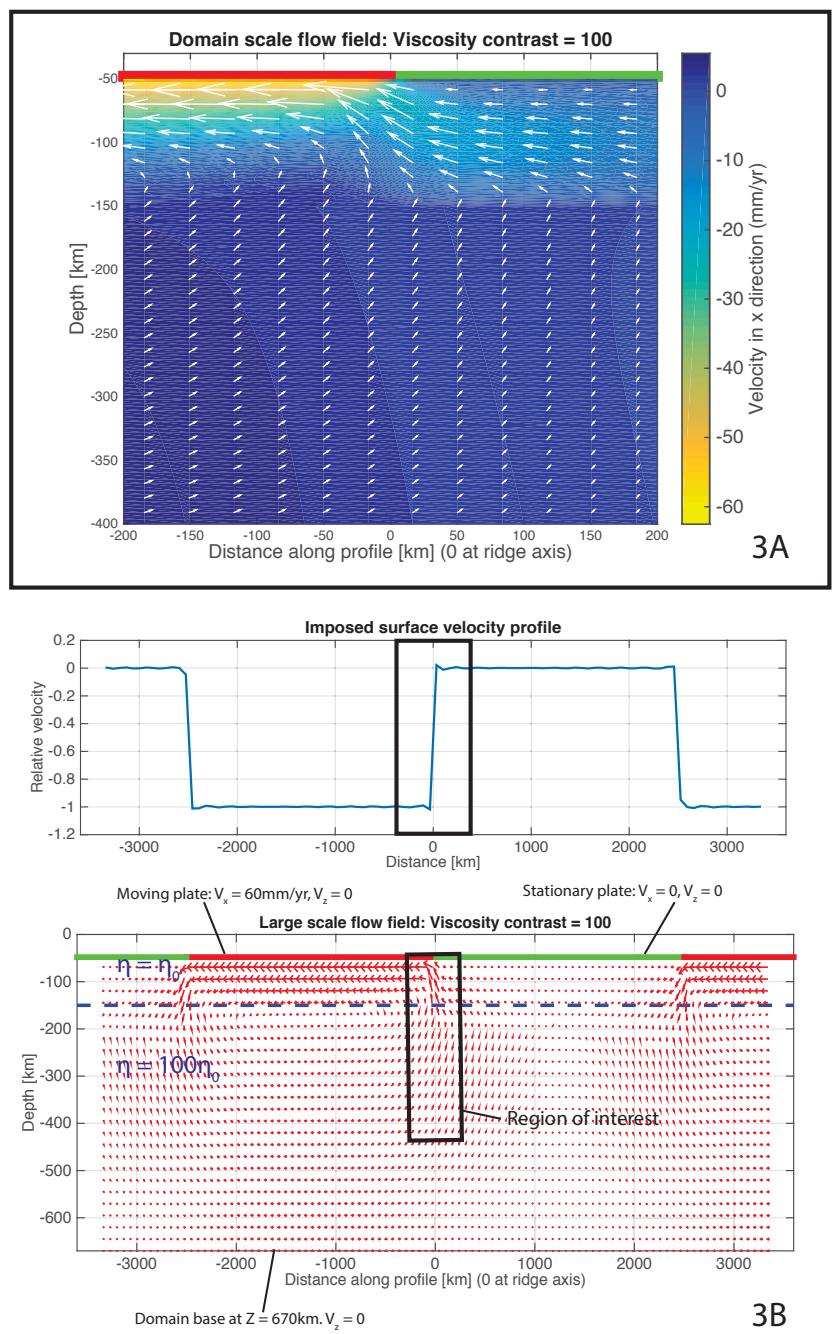